\title{
Medial Closing-Wedge Distal Femoral Varus Osteotomy via Lateral Approach: The New Surgical Technique for Treating Valgus Osteoarthritic Knee
}

Chaturong Pornrattanamaneewong

Siriraj Hospital, Mahidol University

Pakpoom Ruangsomboon

Siriraj Hospital, Mahidol University

Rapeepat Narkbunnam

Siriraj Hospital, Mahidol University

Keerati Chareancholvanich ( $\sim$ keesi93@gmail.com )

Siriraj Hospital, Mahidol University

\section{Research Article}

Keywords: distal femoral varus osteotomy, medial closing wedge, survivorship, osteoarthritis, knee

Posted Date: May 7th, 2021

DOl: https://doi.org/10.21203/rs.3.rs-471882/v1

License: (c) (i) This work is licensed under a Creative Commons Attribution 4.0 International License. Read Full License 


\section{Abstract}

Background and purpose: The medial closing-wedge distal femoral varus osteotomy (MCW-DFVO) was an excellent operation for painful valgus lateral unicompartmental osteoarthritic (OA) knee, especially in the young patient. Originally, it requires a medial approach that has more precarious. On top of that, releasing of the iliotibial band (ITB) that is the deforming force needs added incision. Therefore, this study aims to describe the new surgical technique of MCW-DFVO that uses a lateral approach and lateral plating to treat the valgus OA knee. Additionally, we also reveal the outcomes of our technique as the case series.

Materials and method: Ten patients (12 knees) who underwent MCW-DFVO via a lateral approach were retrospectively reviewed. The inclusion criteria were age $>18$ years, isolated lateral compartmental OA knee, no significant patellofemoral pain, and ROM > 90 degrees. We excluded the inflammatory joint disease, unstable knee (femorotibial joint subluxation $>1 \mathrm{~cm}$ ), and prior surgical procedure. Demographic data, pre- and postoperative ROM, radiographic outcomes, complications, and survivorship were recorded.

Results: The mean age, body mass index, and preoperative ROM were $55.3 \pm 4.0$ years, $25.4 \pm 3.7 \mathrm{~kg} / \mathrm{m} 2 \mathrm{and}$ $113.3 \pm 11.5$ degrees, respectively. The preoperative valgus deformity was $162.3 \pm 4.8$ degrees, and the Final post-operative alignment was $182.3 \pm 2.6$ degrees. Overall mean operative time of this technique was $92.5 \pm 26.7$ minutes. During the follow-up period, post-operative ROM was decreased to $108.8 \pm 11.7$ degrees. One knee required plate removal due to hardware irritation, and another knee required subsequent total knee arthroplasty (TKA) at 1 and 8.5 years after DFVO, respectively. The survivorship of this technique was $91.7 \%$ at the mean survival time of 13.8 years (95\% confidence interval, $11.9-15.7$ years).

Conclusion: This study proposed the new surgical technique of MCW-DFVO via a lateral approach. This technique provided a satisfactory outcome and excellent survivorship. However, further research with a larger sample size was required.

\section{Introduction}

The distal femoral varus osteotomy (DFVO) was the ideal surgical treatment for fail conservative, painful valgus lateral unicompartmental osteoarthritic (OA) knee because it shifts the load from damage lateral compartment to the healthy medial compartment. In the case of valgus deformity, Matsuda et al. [1] found that the lateral femoral condyle was hypoplasia and was severely distorted compared to normal and varus OA knee. Previous investigators found that it provides better outcomes compared to the proximal tibial varus osteotomy [2,3]. Generally, DFVO is recommended for patients who have age $<60$ years, isolated lateral compartmental OA knee, no significant patellofemoral pain, high demand activities, and a good range of motion (ROM) [4]. The contraindications include inflammatory joint disease and unstable knee (femorotibial joint subluxation $>1 \mathrm{~cm}$ ) [5].

The surgical techniques of this procedure can be divided into three types; medial closing-wedge (MCW-DFVO), lateral opening-wedge (LOW-DFVO), and dome DFVO (D-DFVO). MCW-DFVO is a common and widely used technique proposed by McDermott et al. [6]. This technique offers a stable osteotomy site, needless to use the bone graft and good results [5,6]. However, MCW-DFVO has several limitations. Originally, it requires a medial approach that has more precarious. On top of that, releasing of the iliotibial band (ITB) that is the critical 
deforming force needs added incision [7]. Moreover, medial plating has not achieved a biomechanical benefit because it was applied at the adductor moment side, which cannot provide a tension band function [5].

Therefore, this study aims to describe the new surgical technique of MCW-DFVO that uses a lateral approach and lateral plating to treat the valgus OA knee. Additionally, we also reveal the outcomes of our technique as the case series.

\section{Materials And Methods}

Our institutional review board approved this study. Ten patients (12 knees) who underwent MCW-DFVO via a lateral approach were retrospectively reviewed. The inclusion criteria were age $>18$ years, isolated lateral compartmental OA knee, no significant patellofemoral pain, and ROM $>90$ degrees. We excluded the inflammatory joint disease, unstable knee (femorotibial joint subluxation $>1 \mathrm{~cm}$ ), and prior surgical procedure. Demographic data, pre- and post-operative ROM, radiographic outcomes, complications, and survivorship were recorded. All procedures were performed in accordance with relevant guidelines.

\section{Preoperative planning}

The mechanical femorotibial angle (FTA) was measured to define the severity of valgus deformity based on bilateral full length standing alignment film. The preoperative mechanical axis was drawn from the center of the femoral head to the talus's center. It indicated where the weight passed through the knee. According to the method of Dugdale et al. [8], the final weight-bearing line was placed at a position $48-50 \%$ across the tibial plateau width from medial to lateral. The acceptable final alignment was 0-3 degree varus (180-183 degrees) of FTA [9]. The angle between the line from the center of the femoral head to the point of $48 \%$ across the tibial plateau width and the line from the center of talus to the point of $48 \%$ coordinate was measured and named radiographic correction angle. Then, the angle between the distal femoral joint line and the proximal tibial joint line was measured and called the condylar angle. This angle could be corrected by releasing ITB intraoperatively. Thus, the predetermined correction angle (ICA) was finally calculated from the radiographic correction angle minus the condylar angle.

The lateral and axial radiographs of the knee were also assessed for sagittal plane deformity and patellofemoral joint conditions. The Rosenberg view [10], a 45 degrees posteroanterior flexion weight-bearing radiograph at of knee, was additionally used to diagnosis the early OA in the posterior compartment of the knee.

\section{Surgical technique}

This surgical technique was established and performed by the senior author $(\mathrm{KC})$. The patient was placed in a supine position on the radiolucent table. This procedure could be performed with or without using the sterile thigh tourniquet. A curvilinear incision was started from Gerdy's tubercle and then along the lateral side of the femoral shaft. The incisional length was approximately $8-10 \mathrm{~cm}$. ITB was identified and released from Gerdy's tubercle(Figure 1A and 1B). Vastus lateralis muscle was detached from the intermuscular septum and retracted anteromedially to visualize the distal femur.

Under fluoroscopic exam, the Kirsch wires (K-wire) were inserted to guide the osteotomy cut. The first K-wire was inserted at the metaphysodiaphyseal junction of the lateral side of the distal femur that was proximal to the trochlear groove. Its direction was aimed parallel to the distal femoral joint line. The second K-wire was then 
inserted with an entry point just distal to the first K-wire. Using an intraoperative goniometer assisted, the direction of the second K-wire was planned to make the angle with the first K-wire equal to ICA. The final direction was confirmed by measuring ICA from a fluoroscopic image.(Figure 2A and 2B)

The Homann's retractor was placed close to the medial cortex and retracted anteromedially to visualize the anterior cortex and protect the vascular structures. Another Homann's retractor was placed close to the posterior cortex and retracted posteriorly to identify the distal femur's posterior cortex. Then, the osteotomy was performed along the first guided wire using an oscillating saw. The plane of the saw blade was set perpendicular to the lateral femoral shaft axis. The anterior, posterior, and lateral cortices were completely cut. The medial cortex's 5 $\mathrm{mm}$ thickness remained to reduce the risk of vascular injury and preserve the stability of the distal femur for the second osteotomy cut. The second osteotomy cut was done along the second K-wire with the remaining $5 \mathrm{~mm}$ thickness of the medial cortex.

In the correction of sagittal plane deformity, the angle setting between two osteotomy planes was crucial. Flexion contracture of the knee could be improved by cutting the second osteotomy with the posterior slope while genu recurvatum could be improved by cutting with anterior slope. After that, the two osteotomies were completely cut using the osteotome, and the cut bone wedge was removed. Without the lateral hinge, the distal femoral fragment could be freely moved and adjusted the position to reduce the geometric deformity of the distal femur-the final alignment in the desired FTA of 0-3 degree varus(Figure 3A, 3B and 3C). After satisfying, two divergent temporary K-wires fixation was done from the anterolateral part of the distal fragment to the posteromedial part of the proximal fragment. The entry points of these wires had not hindered the plate placement.(Figure 4A)

For the fixation technique, the 5-hole titanium distal femoral locking compression plate (DF-LCP, Synthes, Solothurn, Switzerland) was selected and bend into the contour of the distal femur. After creating the tunnel, DFLCP was placed along the center of the lateral side of the distal femur.(Figure 4B) The most distal screw hole was placed just above the intercondylar notch. At least 4 locking screws were inserted into the distal fragments, while at least 3 locking screws were inserted into the proximal fragment via the stab skin incisions. The final alignment, plate, and screw positions were rechecked.(Figure 4C) At the end of the operation, a vacuum drain was placed along with the plate. The fascia sheath was then repaired. Subcutaneous tissue and skin were sutured. The noncompressive dressing was applied.

In the postoperative rehabilitation, isometric quad. riceps exercise and ankle pumping were started as soon as possible to prevent venous thromboembolism. The ROM exercise and walking with toe-touch weight-bearing was allowed in the first operative day. The drain was left in place for 48 hours. Partial weight-bearing was permitted beginning 2 weeks after surgery, and full weight-bearing was permitted after the radiographic union was observed.

\section{Results}

The patients' data were shown in Table 1. The mean age, body mass index, and preoperative ROM were $55.3 \pm$ 4.0 years, $25.4 \pm 3.7 \mathrm{~kg} / \mathrm{m}^{2}$ and $113.3 \pm 11.5$ degrees, respectively. The preoperative valgus deformity was $162.3 \pm$ 4.8 degrees, and the Final postoperative alignment was $182.3 \pm 2.6$ degrees. Overall mean operative time of this technique was $92.5 \pm 26.7$ minutes. During the follow-up period, postoperative ROM was decreased to $108.8 \pm$ 11.7 degrees. One knee required plate removal due to hardware irritation, and another knee required subsequent 
total knee arthroplasty (TKA) at 1 and 8.5 years after DFVO, respectively. The survivorship of this technique was $91.7 \%$ at the mean survival time of 13.8 years (95\% confidence interval, $11.9-15.7$ years). The Kaplan-Meier curve was demonstrated in Figure 5.

\section{Discussion}

Our senior author (KC) proposed the unique surgical technique of MCW-DFVO via a lateral approach for treating isolated lateral compartmental OA knee. It contributed to good outcomes and survivorship. Our technique had the combined advantages of MCW-DFVO and lateral approach, including stable osteotomy site, unnecessary to use the bone graft, ability to release ITB for reducing the deforming and biomechanical-benefit lateral plating. Nevertheless, this technique still had technically demanded. Furthermore, complete osteotomy cut in our technique led to the loss of lateral hinge that affected in decreased stability. But the ability to adjust distal femoral fragment for reducing the geometric deformity was superseded.

Because a small number of patients were suitable for DFVO, most of the previous studies $[9,12-22]$ were case series. We reviewed the previous literature of DFVO and demonstrated the outcomes in Table 2. From a systematic review of Saithna et al. [23], they found that survivorship of DFVO was $64 \%$ to $84 \%$ at 10 years. For the long-term outcomes of DFVO, Kosashvili et al. [16] reported that $48.5 \%$ of patients required subsequent total knee arthroplasty. While $30.3 \%$ and $21.2 \%$ of patients had good and poor functional outcomes, respectively. The mean follow-up time in their series was 15.1 years. Compare to our study, the novel technique provides excellent results. The survivorship of our technique was $91.7 \%$ at the mean survival time of 13.8 years (95\% confidence interval, 11.9 - 15.7 years).

For the complications, a previous systematic review [23] reveals that the most common complications of overall DFVO were hardware irritation that required subsequent removal of the plate. The loss of correction angle was the problem after MCW-DFVO due to inadequate fixation or poor bone quality $[13,24]$. While LOW-DFVO had a higher incidence of delayed union or non-union of the osteotomy site that might be needed bone graft $[9,19]$, our surgical technique could address these problems. However, hardware irritation still existed in our series.

There were several limitations to this study. First, the number of patients was minimal. However, we would like to demonstrate the new surgical technique in this series. In the future, we tried to collect more number of patients and reported the outcomes. Second, because this study was retrospective design, bias and confounder were difficult to control. Furthermore, we had no data about the functional outcome or activity level of the patients after surgery.

\section{Conclusion}

This study proposed the new surgical technique of MCW-DFVO via a lateral approach. This technique provided a satisfactory outcome and good survivorship. However, further study with a larger sample size was required.

\section{Declarations}

\section{Compliance with Ethical standards}


Ethical approval and consent to participate: This study included human participants. It had been approved by Siriraj Institutional (Si 226/2014 ID 221/2557 (EC2)). Informed consent was obtained from all individual participants included in the study. This study was approved by Siriraj Institutional Review Board (SIRB) and retrospectively registered at Thaiclinicaltrial.gov (TCTR202010427002).

Consent for publication: All authors have read and approved the final submitted manuscript.

Availability of data and material: Requests for data not shown in the body of this manuscript can be made to the corresponding author.

Competing Interest: The authors declare that they have no conflict of interest.

Funding: There is no funding source.

\section{Authors' contributions:}

Chaturong Pornrattanamaneewonng, M.D.,M.Sc and Rapeepat Narkbunnam M.D. provided research questions, conducted data collection, analyzed data, discussion and developed the full manuscript. Pakpoom Ruangsomboon M.D. examined all data analysis, detailed the results, statistical calculation and collected and monitored data. Keerati Chareancholvanich M.D. also provided the research question and useful advice manuscript for journal publication.

\section{Acknowledgments}

The authors acknowledge the assistance given by Nichakorn Khomawut with data collection. We also acknowledge Suthipol Udompunthurak, MSc.(Applied Statistics), for his assistance with the statistical analyses.

\section{References}

1. Matsuda S, Miura H, Nagamine R, Mawatari T, Tokunaga M, Nabeyama R, et al. Anatomical analysis of the femoral condyle in normal and osteoarthritic knees. J Orthop Res Off Publ Orthop Res Soc. 2004 Jan;22(1): p. 104-9.

2. Shoji H, Insall J. High tibial osteotomy for osteoarthritis of the knee with valgus deformity. J Bone Joint Surg Am. 1973 Jul;55(5): p. 963-73.

3. Coventry MB. Proximal tibial varus osteotomy for osteoarthritis of the lateral compartment of the knee. $J$ Bone Joint Surg Am. 1987 Jan;69(1): p. 32-8.

4. Tírico LEP, Demange MK, Bonadio MB, Helito CP, Gobbi RG, Pécora JR. Medial Closing-Wedge Distal Femoral Osteotomy: Fixation With Proximal Tibial Locking Plate. Arthrosc Tech. 2015 Dec;4(6): p. e687-695.

5. Puddu G, Cipolla M, Cerullo G, Franco V, Giannì E. Which osteotomy for a valgus knee? Int Orthop. 2010 Feb;34(2): p. 239-47.

6. McDermott AG, Finklestein JA, Farine I, Boynton EL, Maclntosh DL, Gross A. Distal femoral varus osteotomy for valgus deformity of the knee. J Bone Joint Surg Am. 1988 Jan;70(1): p. 110-6.

7. Favorito PJ, Mihalko WM, Krackow KA. Total knee arthroplasty in the valgus knee. J Am Acad Orthop Surg. 2002 Feb;10(1): p. 16-24. 
8. Dugdale TW, Noyes FR, Styer D. Preoperative planning for high tibial osteotomy. The effect of lateral tibiofemoral separation and tibiofemoral length. Clin Orthop. 1992 Jan;(274): p. 248-64.

9. Stähelin T, Hardegger F, Ward JC. Supracondylar osteotomy of the femur with use of compression. Osteosynthesis with a malleable implant. J Bone Joint Surg Am. 2000 May;82(5): p. 712-22.

10. Rosenberg TD, Paulos LE, Parker RD, Coward DB, Scott SM. The forty-five-degree posteroanterior flexion weight-bearing radiograph of the knee. J Bone Joint Surg Am. 1988 Dec;70(10): p. 1479-83.

11. Krettek C, Miclau T, Grün O, Schandelmaier P, Tscherne H. Intraoperative control of axes, rotation and length in femoral and tibial fractures. Technical note. Injury. 1998;29 Suppl 3: p. C29-39.

12. Finkelstein JA, Gross AE, Davis A. Varus osteotomy of the distal part of the femur. A survivorship analysis. J Bone Joint Surg Am. 1996 Sep;78(9): p. 1348-52.

13. Wang J-W, Hsu C-C. Distal femoral varus osteotomy for osteoarthritis of the knee. J Bone Joint Surg Am. 2005 Jan;87(1): p. 127-33.

14. Backstein D, Morag G, Hanna S, Safir O, Gross A. Long-term follow-up of distal femoral varus osteotomy of the knee. J Arthroplasty. 2007 Jun;22(4 Suppl 1): p. 2-6.

15. Omidi-Kashani F, Hasankhani IG, Mazlumi M, Ebrahimzadeh MH. Varus distal femoral osteotomy in young adults with valgus knee. J Orthop Surg. 2009 May 13; p. 4:15.

16. Kosashvili Y, Safir O, Gross A, Morag G, Lakstein D, Backstein D. Distal femoral varus osteotomy for lateral osteoarthritis of the knee: a minimum ten-year follow-up. Int Orthop. 2010 Feb;34(2): p. 249-54.

17. Das DH, Sijbesma T, Hoekstra H, W. van Leeuwen. Distal femoral opening-wedge osteotomy for lateral compartment osteoarthritis of the knee. Open Access Surg. 2008;1: p. 25-9.

18. Zarrouk A, Bouzidi R, Karray B, Kammoun S, Mourali S, Kooli M. Distal femoral varus osteotomy outcome: Is associated femoropatellar osteoarthritis consequential? Orthop Traumatol Surg Res OTSR. 2010 Oct;96(6): p. 632-6.

19. Jacobi M, Wahl P, Bouaicha S, Jakob RP, Gautier E. Distal femoral varus osteotomy: problems associated with the lateral open-wedge technique. Arch Orthop Trauma Surg. 2011 Jun;131(6): p. 725-8.

20. Thein R, Bronak S, Thein R, Haviv B. Distal femoral osteotomy for valgus arthritic knees. J Orthop Sci Off J Jpn Orthop Assoc. 2012 Nov;17(6): p. 745-9.

21. Dewilde TR, Dauw J, Vandenneucker H, Bellemans J. Opening wedge distal femoral varus osteotomy using the Puddu plate and calcium phosphate bone cement. Knee Surg Sports Traumatol Arthrosc Off J ESSKA. 2013 Jan;21(1): p. 249-54.

22. Saithna A, Kundra R, Getgood A, Spalding T. Opening wedge distal femoral varus osteotomy for lateral compartment osteoarthritis in the valgus knee. The Knee. 2014 Jan;21(1): p. 172-5.

23. Saithna A, Kundra R, Modi CS, Getgood A, Spalding T. Distal femoral varus osteotomy for lateral compartment osteoarthritis in the valgus knee. A systematic review of the literature. Open Orthop J. 2012;6: p. 313-9.

24. Edgerton BC, Mariani EM, Morrey BF. Distal femoral varus osteotomy for painful genu valgum. A five-to-11year follow-up study. Clin Orthop. 1993 Mar;(288): p. 263-9.

\section{Tables}

Table 1. Data of the patients 


\begin{tabular}{|c|c|c|c|c|c|c|c|c|c|c|}
\hline \multirow[t]{2}{*}{ No. } & \multirow[t]{2}{*}{ Gender } & \multirow{2}{*}{$\begin{array}{l}\text { Age } \\
(y r)\end{array}$} & \multirow[t]{2}{*}{ Side } & \multirow{2}{*}{$\begin{array}{l}\text { BMI } \\
\left(\mathrm{kg} / \mathrm{m}^{2}\right)\end{array}$} & \multicolumn{2}{|c|}{$\begin{array}{l}\text { Range of } \\
\text { motion }\left({ }^{\circ}\right)\end{array}$} & \multicolumn{2}{|l|}{ FTA $\left(^{\circ}\right)$} & \multirow{2}{*}{$\begin{array}{l}\text { Follow- } \\
\text { up } \\
\text { time } \\
(\mathrm{yr})\end{array}$} & \multirow[t]{2}{*}{ Complications } \\
\hline & & & & & Preop & Postop & Preop & Postop & & \\
\hline 1 & Female & 59 & Right & 27.9 & 120 & 110 & 166 & 184 & 14.8 & - \\
\hline 2 & Male & 47 & Right & 23.4 & 120 & 100 & 168 & 180 & 11.1 & - \\
\hline \multirow[t]{2}{*}{3} & Female & 59 & Right & 31.5 & 120 & 120 & 161 & 183 & 11.0 & - \\
\hline & Female & 60 & Left & 31.4 & 120 & 120 & 159 & 183 & 10.2 & - \\
\hline 4 & Male & 53 & Right & 24.0 & 120 & 120 & 163 & 185 & 6.3 & - \\
\hline 5 & Female & 58 & Right & 26.8 & 110 & 120 & 160 & 179 & 7.8 & - \\
\hline \multirow[t]{2}{*}{6} & Female & 56 & Right & 19.1 & 90 & 90 & 156 & 186 & 8.5 & $\begin{array}{l}\text { Converse to } \\
\text { TKA }\end{array}$ \\
\hline & Female & 57 & Left & 20.9 & 120 & 105 & 169 & 183 & 8.7 & Plate removal \\
\hline 7 & Female & 54 & Right & 25.5 & 120 & 120 & 155 & 185 & 5.0 & - \\
\hline 8 & Male & 49 & Right & 25.1 & 110 & 90 & 169 & 178 & 5.7 & - \\
\hline 9 & Female & 54 & Right & 24.9 & 90 & 110 & 161 & 182 & 5.1 & - \\
\hline 10 & Female & 57 & Right & 24.2 & 120 & 100 & 161 & 180 & 5.0 & - \\
\hline
\end{tabular}

BMI: body mass index, FTA: femorotibial angle, TKA: total knee arthroplasty

Table 2. Previous studies and outcomes of distal femoral varus osteotomy (DFVO) 


\begin{tabular}{|c|c|c|c|c|c|c|}
\hline Authors & Year & $\mathrm{n}$ & $\begin{array}{l}\text { Aimed final } \\
\text { alignment }\end{array}$ & Implant & $\begin{array}{l}\text { Follow-up } \\
\text { time } \\
\text { (mean, } \\
\text { range) }\end{array}$ & Survivorship \\
\hline \multicolumn{7}{|c|}{ Medial closing-wedge DFVO } \\
\hline Finkelstein et al. & 1996 & 21 & $0^{\circ} \mathrm{FTA}$ & Blade plate & $\begin{array}{l}133(97-240) \\
\text { mons }\end{array}$ & $64 \%$ at $10 \mathrm{yrs}$ \\
\hline Stähelin et al. & 2000 & 21 & $1-3^{\circ}$ varus FTA & Semitubular plate & $\begin{array}{l}5(2-12) \\
\text { yrs }\end{array}$ & NA \\
\hline Wang et al. & 2005 & 30 & $0^{\circ} \mathrm{FTA}$ & Blade plate & $\begin{array}{l}99(61-169) \\
\text { mons }\end{array}$ & $87 \%$ at $10 \mathrm{yrs}$ \\
\hline Backstein et al. & 2007 & 40 & $0^{\circ} \mathrm{FTA}$ & Blade plate & $\begin{array}{l}123(39-245) \\
\text { mons }\end{array}$ & $82 \%$ at $10 \mathrm{yrs}$ \\
\hline $\begin{array}{l}\text { Omidi-Kashani } \\
\text { et al. }\end{array}$ & 2009 & 23 & $0^{\circ} \mathrm{FTA}$ & Blade plate & $\begin{array}{l}\text { 16.3(8-25) } \\
\text { Mon }\end{array}$ & NA \\
\hline Kosashvili et al. & 2010 & 33 & $0^{\circ} \mathrm{FTA}$ & Blade plate & $\begin{array}{l}15.1(10-25) \\
\text { yrs }\end{array}$ & $\begin{array}{l}51.5 \% \text { at } 15.6 \\
\text { yrs }\end{array}$ \\
\hline Lateral opening- $w$ & dge DF & & & & & \\
\hline Das et al. & 2008 & 12 & $3^{\circ}$ valgus FTA & Puddu plate & $\begin{array}{l}74(51-89) \\
\text { mons }\end{array}$ & NA \\
\hline Zarrouk et al. & 2010 & 22 & $2-3^{\circ}$ valgus FTA & $\begin{array}{l}\text { Strelitzia type blade } \\
\text { plate }\end{array}$ & $\begin{array}{l}54(36-132) \\
\text { mons }\end{array}$ & $91 \%$ at 8 yrs \\
\hline Jacobi et al. & 2011 & 14 & NA & Tomofix plate & $\begin{array}{l}45(26-64) \\
\text { mons }\end{array}$ & NA \\
\hline Thein et al. & 2012 & 7 & $0^{\circ} \mathrm{FTA}$ & Puddu plate & $6.5 \mathrm{yrs}$ & $\begin{array}{l}100 \% \text { at } 6.5 \\
\text { yrs }\end{array}$ \\
\hline Dewilde et al. & 2013 & 16 & $2^{\circ}$ varus FTA & Puddu plate & $\begin{array}{l}68(31-127) \\
\text { mons }\end{array}$ & $82 \%$ at $7 \mathrm{yrs}$ \\
\hline Saithna et al. & 2014 & 21 & $0^{\circ} \mathrm{FTA}$ & $\begin{array}{l}\text { Tomofix or Puddu } \\
\text { plate }\end{array}$ & $\begin{array}{l}4.5(1.6-9.2) \\
\text { yrs }\end{array}$ & $79 \%$ at 5 yrs \\
\hline
\end{tabular}

FTA: femorotibial angle, NA: not applicable

\section{Figures}




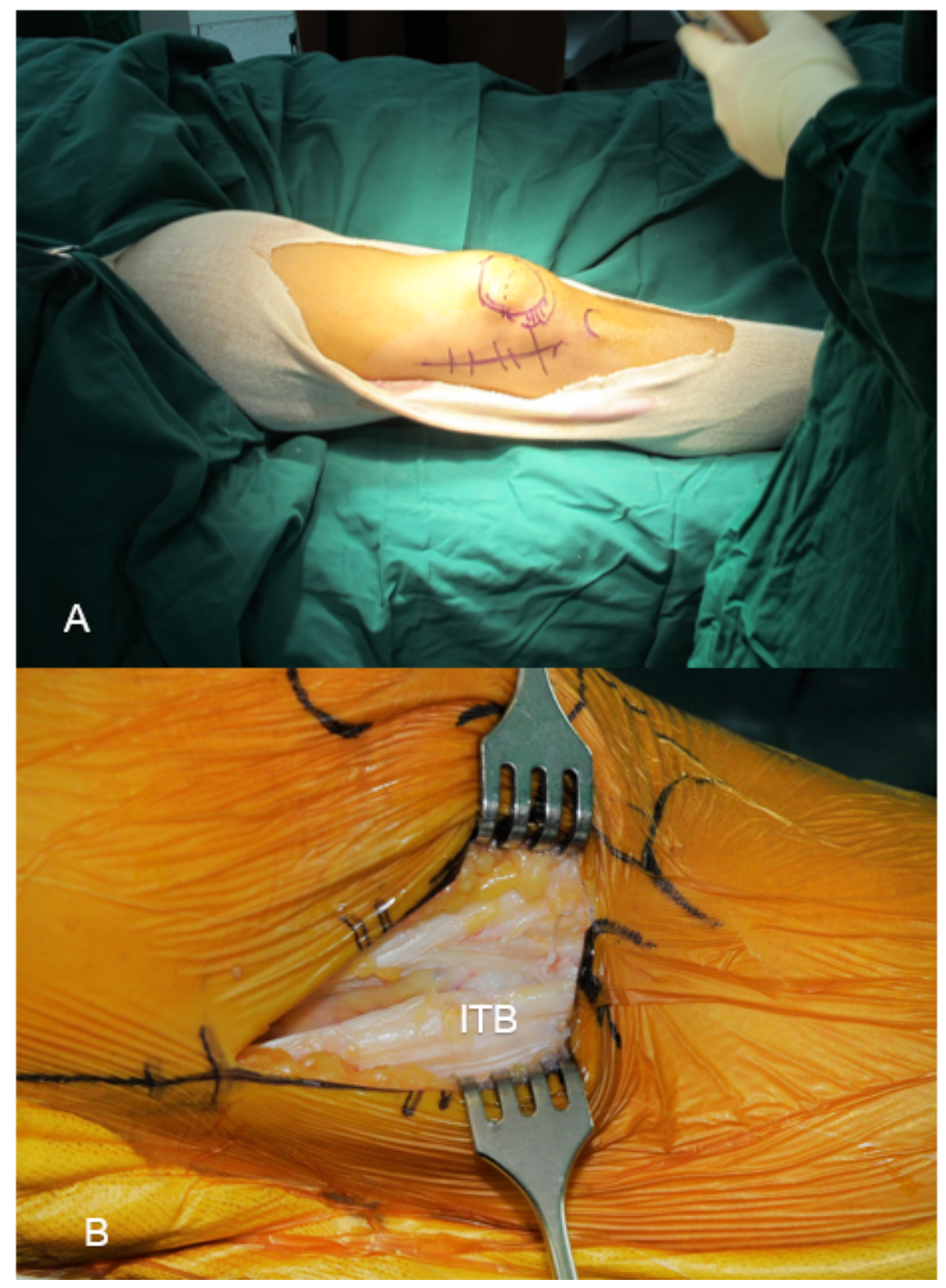

\section{Figure 1}

A. The patient was placed in a supine position on the radiolucent table. A curvilinear incision was started from Gerdy's tubercle and then along the lateral side of the femoral shaft. B. The incisional length was approximately 8-10 cm. ITB was identified and released from Gerdy's tubercle 


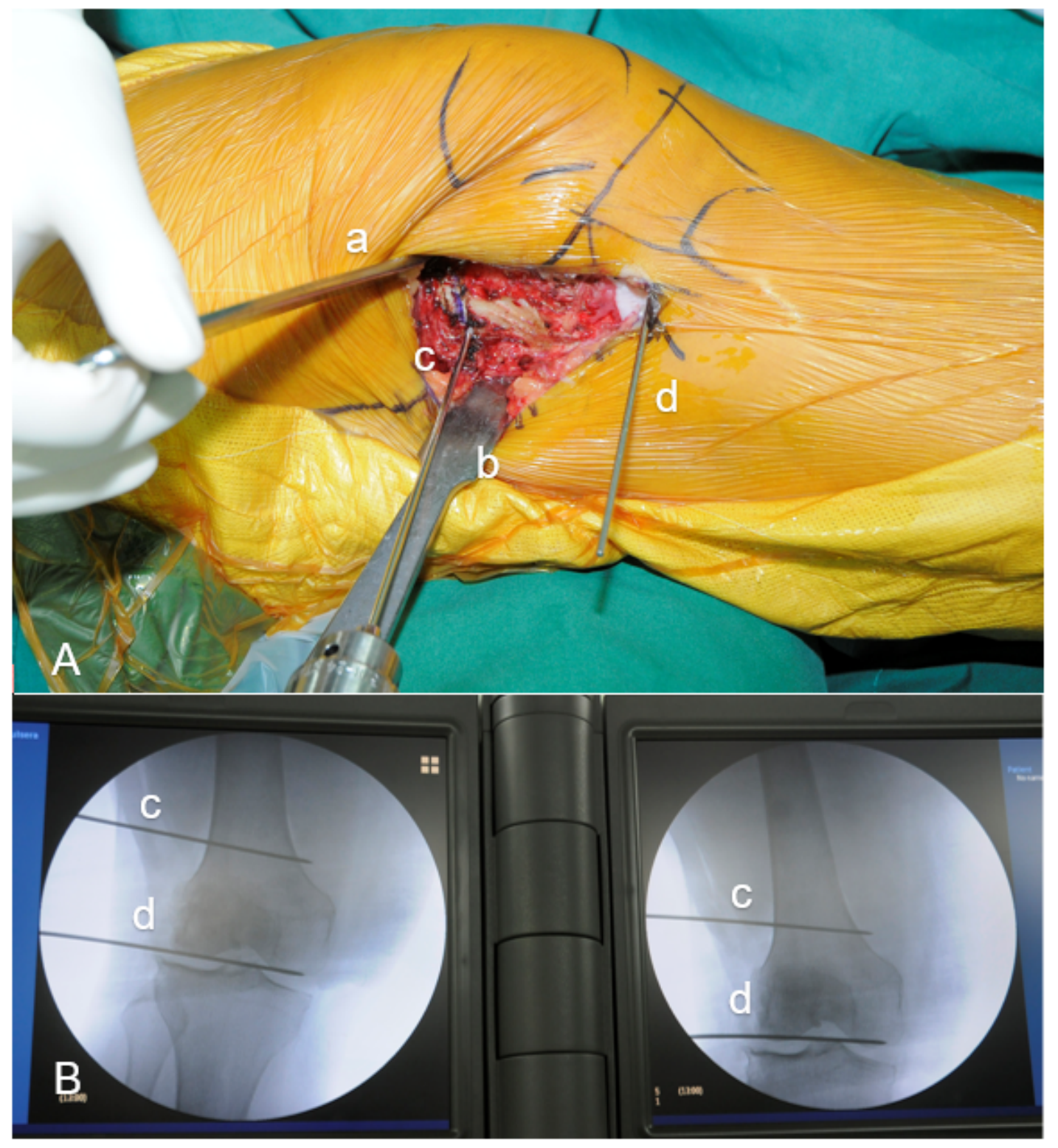

\section{Figure 2}

A. The Homann's retractor (a) was placed close to the medial cortex. Another Homann's retractor (b) was placed close to the posterior cortex and retracted posteriorly to identify the distal femur's posterior cortex. B. The fluoroscopic exam shjow the first K-wire (c) was inserted at the metaphysodiaphyseal junction of the lateral side of the distal femur that was proximal to the trochlear groove. The second K-wire (d) was then inserted with an entry point just distal to the first K-wire. 

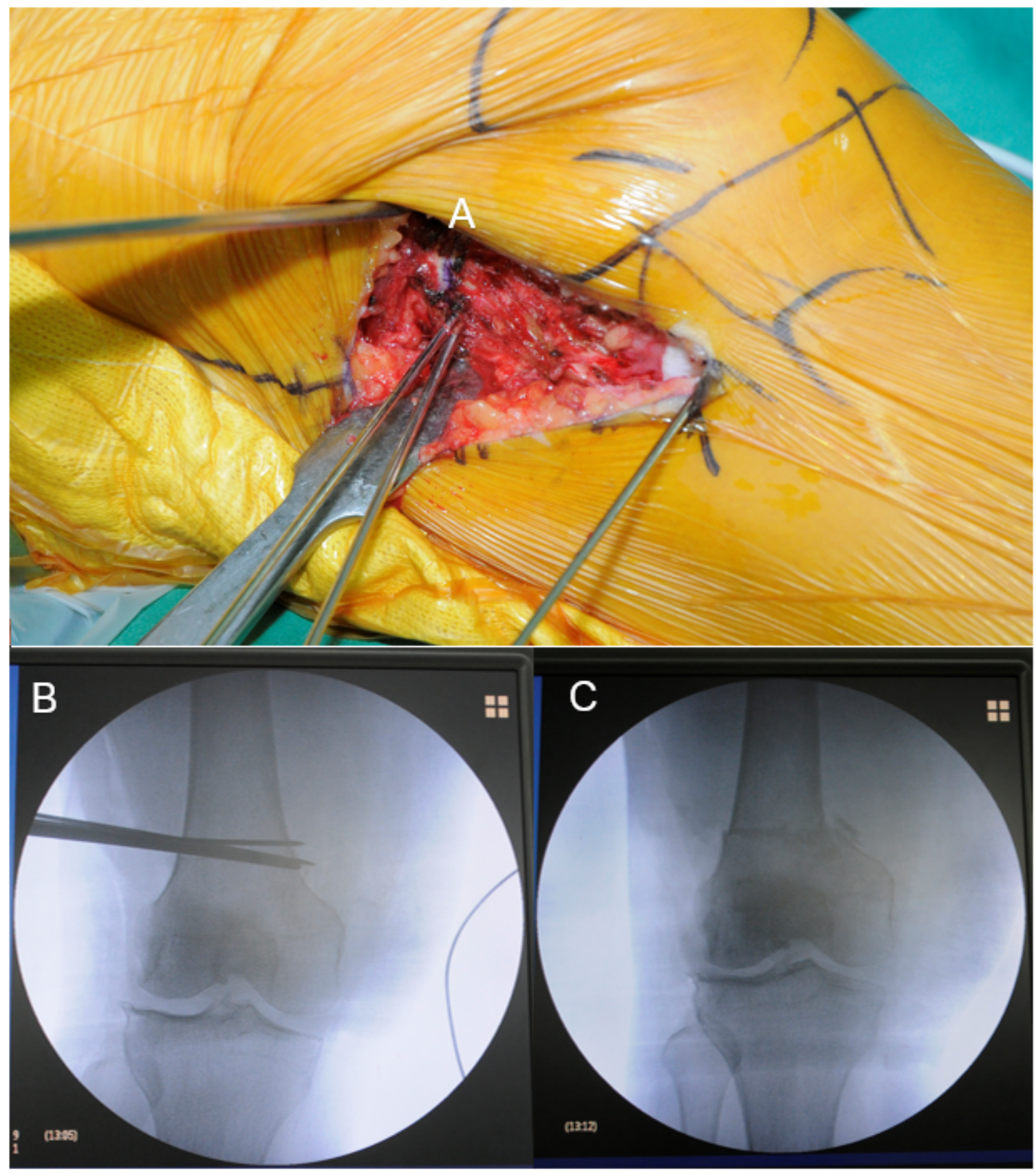

\section{Figure 3}

The osteotomy $(A)$ was performed along the guided wire using an oscillating saw. After that, the two osteotomies were completely cut using the osteotome (B), and the cut bone wedge was removed. Without the lateral hinge, the distal femoral fragment could be freely moved and adjusted the position to reduce the geometric deformity of the distal femur (C). 

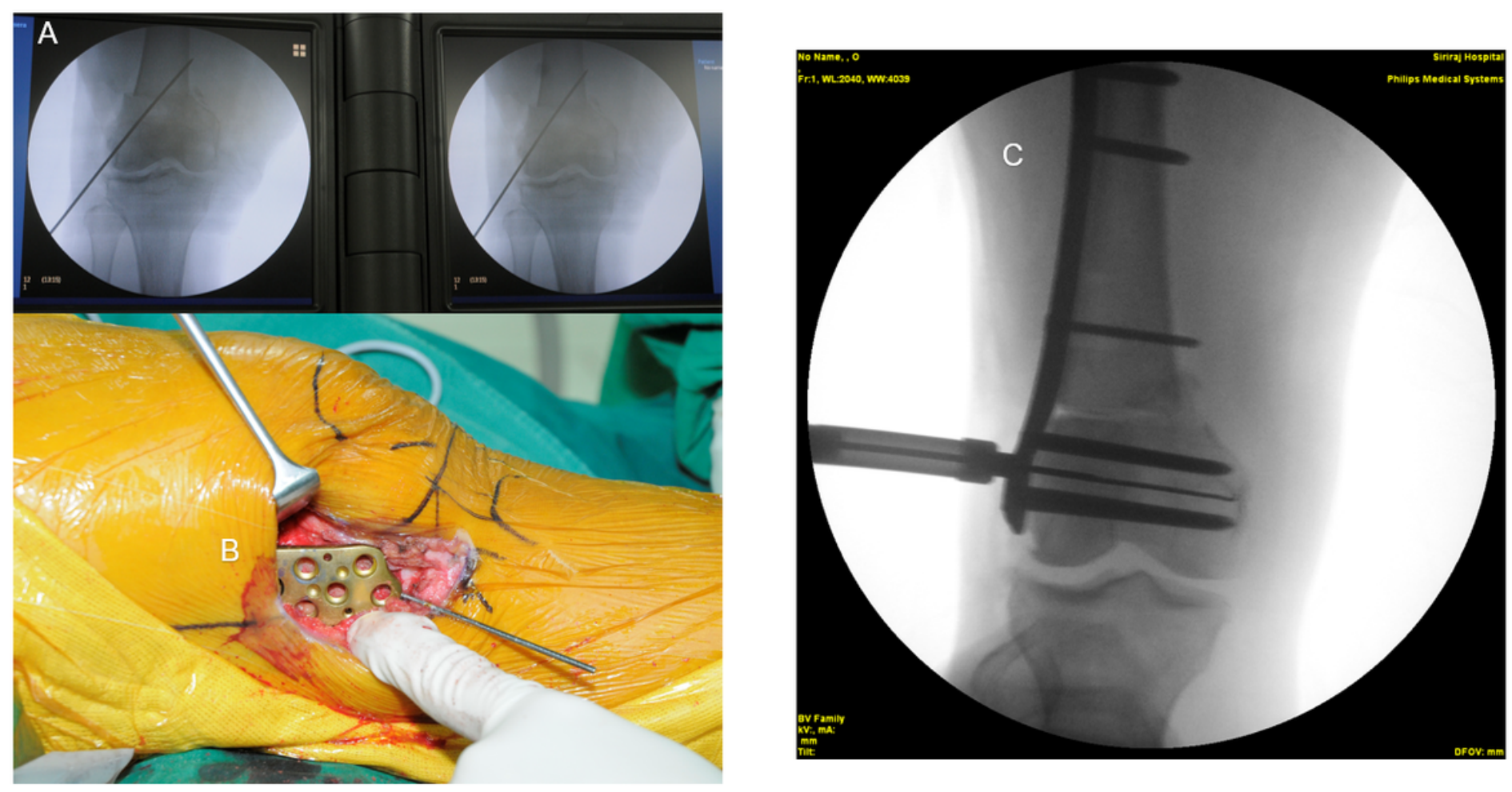

Figure 4

After satisfying, two divergent temporary K-wires fixation was done from the anterolateral part of the distal fragment to the posteromedial part of the proximal fragment (A). After creating the tunnel, DF-LCP was placed along the center of the lateral side of the distal femur (B). The final alignment, plate, and screw positions were rechecked (C). 


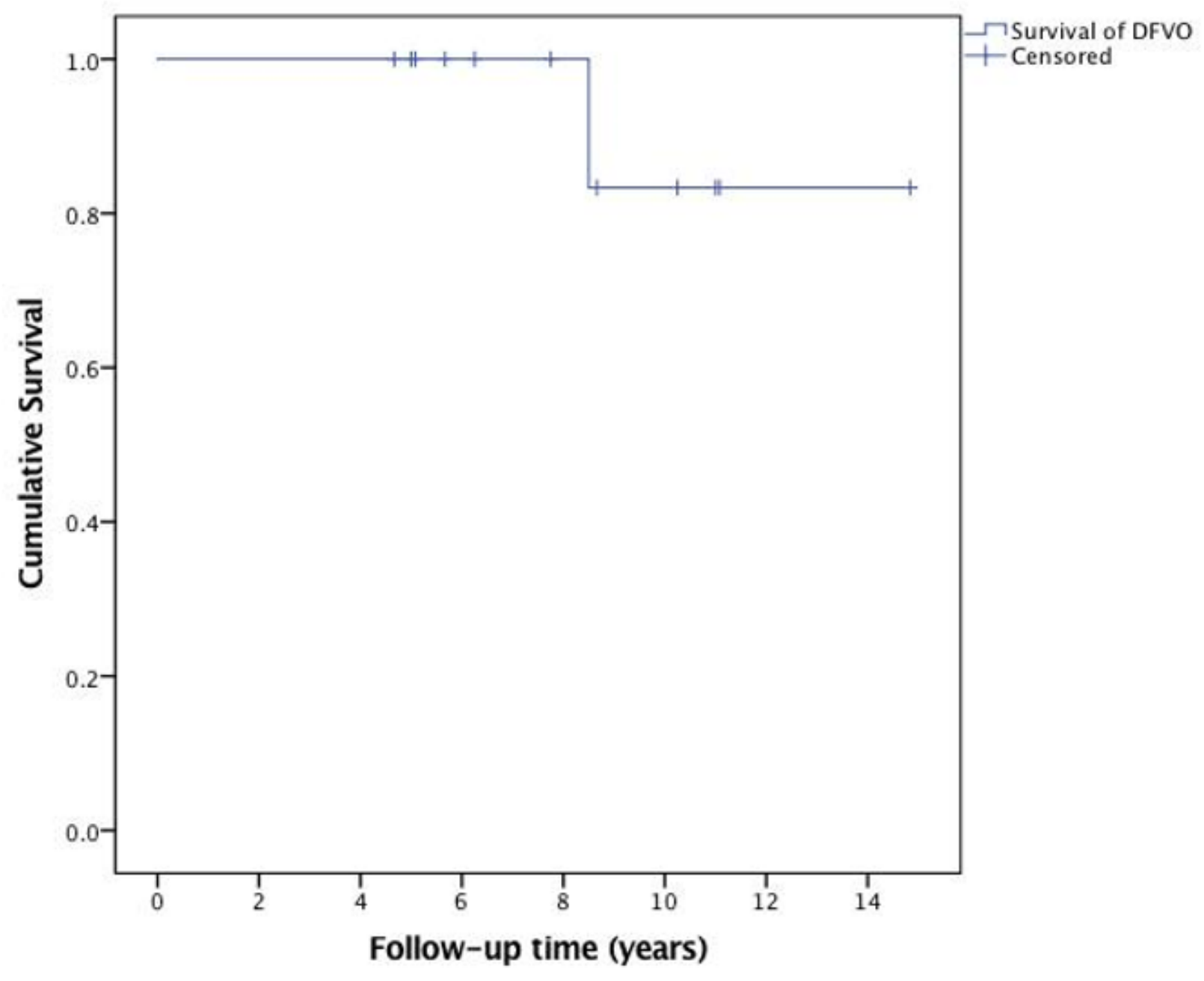

Figure 5

The Kaplan-Meier curve of the medial closing-wedge (MCW-DFVO) in the study. 